\title{
Preparation of polyurethane-acrylate and silica nanoparticle hybrid composites by a free radical network formation method
}

\author{
HADI NEMATI ${ }^{1,2}$, HOSSEIN ROGHANI-MAMAQANI ${ }^{1,2, *(D)}$ and MEHDI SALAMI-KALAJAHI ${ }^{1,2}$ \\ ${ }^{1}$ Department of Polymer Engineering, Sahand University of Technology, P.O. Box 5331817634, Tabriz, Iran \\ ${ }^{2}$ Institute of Polymeric Materials, Sahand University of Technology, P.O. Box 5331817634, Tabriz, Iran \\ *Author for correspondence (r.mamaghani@sut.ac.ir)
}

MS received 21 February 2019; accepted 21 April 2019

\begin{abstract}
In this study, hybrid composites of polyurethane-acrylate (PUA) and silica nanoparticle were prepared by a radical method. For this aim, silica nanoparticles were chemically functionalized with 3-methacryloxypropyltrimethoxysilane. Polyurethane was synthesized and then modified with 2-hydroxyethyl methacrylate to yield PUA. Then, different amounts of modified-silica were used to prepare PUA composites by the addition of an ethylene glycol dimethacrylate crosslinker. Fourier-transform infrared spectroscopy confirmed the successful functionalization of silica nanoparticles and the preparation of PUA. Structural investigation of the functionalized-nanoparticles and also nanocomposites was carried out using $\mathrm{X}$-ray diffraction and electron microscopy. According to the thermal gravimetric analysis results, char residue of $\mathrm{HSiO}_{2}$ is $86.6 \%$, which decreases to $81.3 \%$ in the case of $\mathrm{MSiO}_{2}$ as a result of its modifier degradation content of 5.3\%. PUAS5 shows main decomposition temperatures of 396.5 and $454.9^{\circ} \mathrm{C}$ and also char content of $5.7 \%$ at $700^{\circ} \mathrm{C}$. The high amount of $\mathrm{MSiO}_{2}$ can also be resulted in higher degree of crosslinking and therefore higher thermal stabilities and char residue.
\end{abstract}

Keywords. Polyurethane acrylate; nanocomposite; silica nanoparticle; radical method; thermal properties.

\section{Introduction}

Polymer nanocomposites are one of the important categories of advanced materials with improved mechanical and thermal properties. In comparison with the ordinary composites, nanocomposites were extensively considered because of strong interactions between their structural components of the polymeric matrix and nanodimensional filler. Polyurethane (PU) is an applicable polymer which can be used in wide variety of applications, such as composites, coatings, flexible and rigid foams, adhesives and sealants [1-3]. Polyurethaneacrylate (PUA) is a PU which is end-capped with acrylic functionality by using hydroxyl group containing unsaturated acrylic monomers of hydroxyethyl acrylate (HEA) and hydroxyethyl methacrylate (HEMA). The hard segments of PUA generally consist of isocyanate and acrylic functionality, and the soft segments are formed from polyols in most cases [4-7]. PUA exhibits excellent impact strength and also high adhesion. However, low-thermal stability limits its application in wide variety of engineering fields. Most of PUA characteristics can be improved by the incorporation of inorganic components and the formation of hybrid materials [8-10].

Organic/inorganic hybrid materials combine beneficial characteristics of organic polymers like processability with the useful properties of inorganic domains such as thermal stability. Silica nanoparticles have widely been used because of their effects on lowering shrinkage during curing and decreasing thermal expansion coefficients [11-13]. Strong interactions between the silica nanoparticles and silanol groups with PU chains can result in their high degree of dispersion in the PU matrix [14]. However, simple blending of silica nanoparticles with polymers is often restricted as a result of the large amount of their hydroxyl groups and consequently, their aggregation because of weak interactions between the two phases [15]. To overcome this problem, silica nanoparticles can be functionalized with different chemicals for enhancing their dispersion and compatibility with the polymer matrix not only in PU composites, but also in various polymer composites [16-18].

In the case of PUA composites, Qiu and coworkers [19] prepared nanocomposites of silica/waterborne polyurethane acrylate (WPUA) using a sol-gel process, where $T_{\mathrm{g}}$ of the hybrid composites increased with the addition of inorganic domain content. WPUA was prepared from isophorone diisocyanate and polyether polyol as the main components of the PU oligomer and HEMA as the hydroxyl group containing unsaturated acrylic modifier. Finally, silica/WPUA nanocomposites were prepared by using coupling agents of tetraethoxysilane and 3-glycidyloxypropyltrimethoxysilane and also application of the sol-gel reaction. Wang and coworkers [20] prepared nanocomposites via photopolymerization of WPUA in the presence of octavinyl polyhedral oligomeric silsesquioxane. They showed that the thermal 
Table 1. Sample names with a brief description.

\begin{tabular}{ll}
\hline Sample & \multicolumn{1}{c}{ Description } \\
\hline $\mathrm{HSiO}_{2}$ & Hydroxylated silica nanoparticles \\
$\mathrm{MSiO}_{2}$ & MPS-modified $\mathrm{HSiO}_{2}$ \\
$\mathrm{PU}$ & Polyurethane \\
$\mathrm{PUA}$ & Polyurethane-acrylate \\
$\mathrm{CPUA}$ & Cured PUA \\
PUAS1 & PUA nanocomposite with 1 wt $\%$ of $\mathrm{MSiO}_{2}$ \\
PUAS3 & PUA nanocomposite with $3 \mathrm{wt} \%$ of $\mathrm{MSiO}_{2}$ \\
PUAS5 & PUA nanocomposite with $4 \mathrm{wt} \%$ of $\mathrm{MSiO}_{2}$ \\
\hline
\end{tabular}

properties of these hybrid composites were higher than the neat WPUA. Lately, they used HEA-modified graphene oxide in the preparation of PUA composites with high-thermal stability using UV curing technology [21]. They showed that strong interfacial interactions were formed between the uniformly dispersed-modified layers and PUA as a result of UV cross-linking.

A free radical method can be used for network formation in PUA and its composites. Similar to the preparation of hybrid polymer gels that the network formation occurs by using crosslinkers, and PUA hybrid composites can also be prepared by using ethylene glycol dimethacrylate (EGDMA) as the free radical crosslinker. Therefore, double bonds of PUA, modified silica and EGDMA crosslinker form a network by thermal dissociation of azobisisobutyronitrile (AIBN). Here, hybrid composites of PUA and silica nanoparticles were prepared by using the radical method. To this end, silica nanoparticles were modified with 3-methacryloxy propyltrimethoxysilane (MPS) and incorporated into the PUA matrix in different contents by the free radical method. PUA was also prepared by a sequential reaction of hexamethylene diisocyanate (HMDI) and polyethylene glycol (PEG) and its end-capping with HEMA. This well-tuned process resulted in covalent bending between the PUA matrix and also modified silica nanoparticles. Finally, structural, morphological and thermal characteristics of the nanocomposites were investigated using different methods. Sample names with a brief description are given in table 1 .

\section{Experimental}

\subsection{Materials}

PEG $\left(M_{\mathrm{n}}=600\right.$ Da, Sigma-Aldrich), silica nanoparticles $\left(\mathrm{SiO}_{2}\right.$, Tecnan-Nanomat, Spain) and EGDMA (SigmaAldrich) were used as received. HMDI, AIBN, HEMA, MPS, triethylamine (TEA) acetone, tetrahydrofuran (THF), ethanol, methanol and acetic acid were received from Merck Company.

\subsection{Preparation of hydrophilic $\mathrm{SiO}_{2}\left(\mathrm{HSiO}_{2}\right)$}

According to the literature [22,23], $\mathrm{SiO}_{2}(2.5 \mathrm{~g})$ was mixed in distilled water $(100 \mathrm{ml})$ and sonicated for $30 \mathrm{~min}$. After addition of $\mathrm{NaOH}(1.5 \mathrm{~g})$ and stirring at $60^{\circ} \mathrm{C}$ for $24 \mathrm{~h}$, acetic acid was gradually added for neutralization. Finally, $\mathrm{HSiO}_{2}$ was obtained after centrifugation of the mixture for $10 \mathrm{~min}$, washing the solid with methanol, and drying at $80^{\circ} \mathrm{C}$ for a day.

\subsection{Functionalization of $\mathrm{HSiO}_{2}$ by MPS to obtain $\mathrm{MSiO}_{2}$}

According to the literature [24,25], $\mathrm{HSiO}_{2}(2 \mathrm{~g})$ was mixed in a $100 \mathrm{ml}$ ethanol and water mixture (volumetric ratio of 8:2) and sonicated for $30 \mathrm{~min}$. Then, TEA $(15 \mathrm{ml})$ was added and agitated at $50^{\circ} \mathrm{C}$ for $2 \mathrm{~h}$. In another flask, MPS (1 ml) was added to the ethanol and water mixture (volumetric ratio of 9:1) and $\mathrm{pH}$ of the solution was adjusted to $3-4$ by the addition of acetic acid solution ( 0.1 molar) for the progression of the hydrolysis process by stirring at $50^{\circ} \mathrm{C}$ for $2 \mathrm{~h}$. Afterwards, the MPS solution was gradually added on $\mathrm{HSiO}_{2}$ dispersion and stirred at $50^{\circ} \mathrm{C}$ for $8 \mathrm{~h}$. Finally, $\mathrm{MSiO}_{2}$ was obtained by centrifugation of the mixture at $8000 \mathrm{rpm}$ for $15 \mathrm{~min}$, washing with acetone, and drying at $60^{\circ} \mathrm{C}$ for a day.

\subsection{Preparation of PUA resin}

Isocyanate-terminated PU was synthesized in an isocyanate to hydroxyl molar ratio of $2: 1$. For this purpose, HDI $(1 \mathrm{ml})$ was mixed with THF $(10 \mathrm{ml})$ in a flask. PEG $(1.66 \mathrm{ml})$ was gradually added into the flask and prepolymerization of $\mathrm{PU}$ was accomplished in a nitrogen atmosphere at $60^{\circ} \mathrm{C}$ for $3 \mathrm{~h}$. Then, the flask content was cooled to $50^{\circ} \mathrm{C}$ and HEMA $(0.75$ $\mathrm{ml}$ ) was gradually added into the flask. For dilution of the mixture, THF $(10 \mathrm{ml})$ was added and the temperature was kept at $50^{\circ} \mathrm{C}$ for $3 \mathrm{~h}$ to yield PUA resin (figure 1).

\subsection{Preparation of $\mathrm{MSiO}_{2} / \mathrm{PUA}$ hybrid composites}

After synthesis of PUA resin, it was sequentially used in the preparation of $\mathrm{MSiO}_{2} / \mathrm{PUA}$ hybrid composites with different weight percents of $\mathrm{MSiO}_{2}$ (table 2). To this end, temperature was increased from 50 to $65^{\circ} \mathrm{C}$. EGDMA as the crosslinker $(0.23 \mathrm{ml})$ was added in a molar ratio of $0.2: 1$ with respect to HEMA. Then, after dispersing $\mathrm{MSiO}_{2}$ in THF and sonication for $10 \mathrm{~min}$, it was added into the flask at $65^{\circ} \mathrm{C}$. Then, AIBN in $2 \mathrm{wt} \%$ with respect to HEMA and EGDMA was dispersed in THF and added into the flask. Finally, the free radical reaction was maintained at $65^{\circ} \mathrm{C}$ for $2 \mathrm{~h}$ till the reaction medium changed to the gel state. The product was dried at $50^{\circ} \mathrm{C}$ for a day to yield $\mathrm{MSiO}_{2} / \mathrm{PUA}$ hybrid composites (figure 2).

\subsection{Characterization}

Fourier-transform infrared (FTIR) spectroscopy was performed on a Bruker spectrometer (Germany) using $\mathrm{KBr}$ 


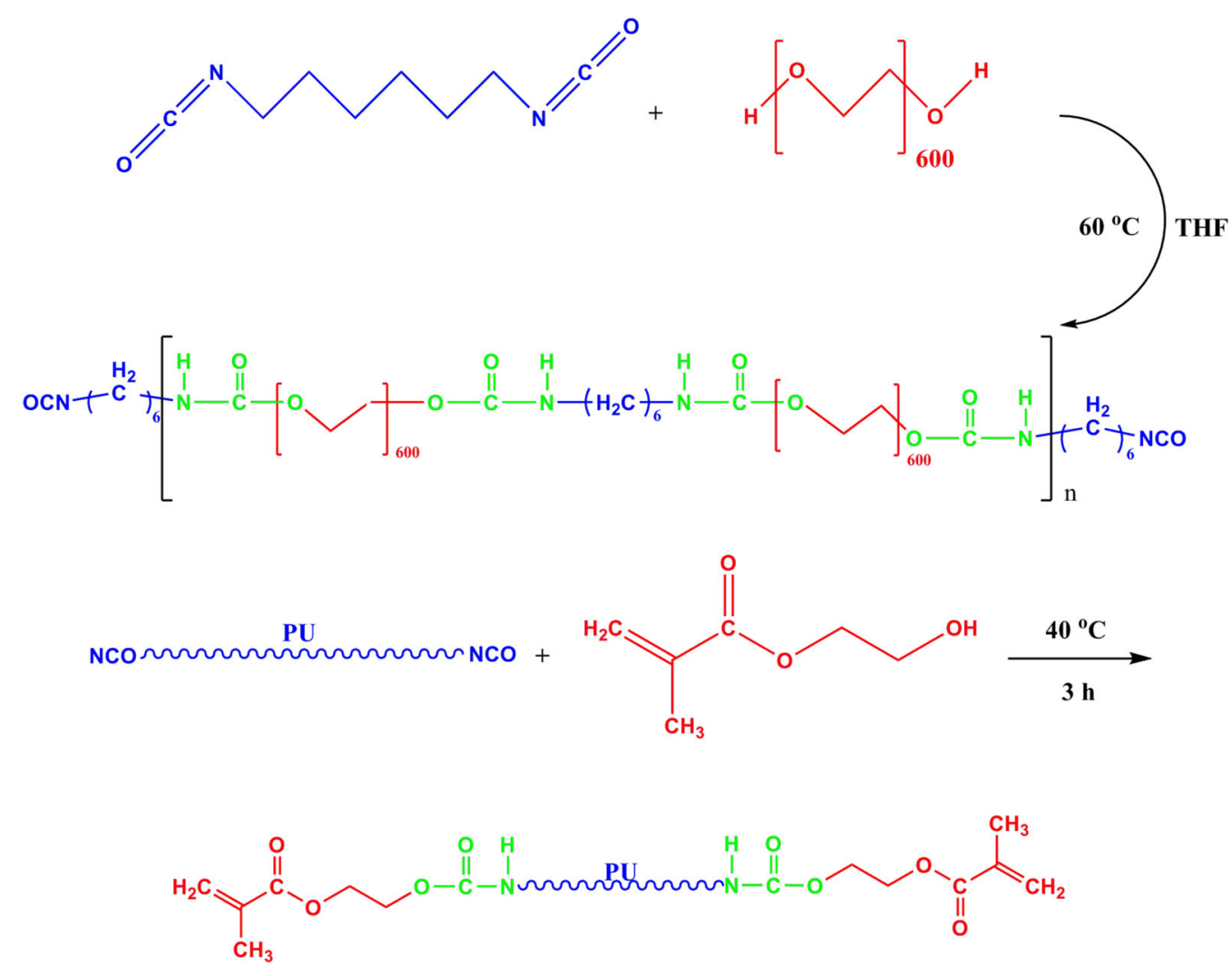

Figure 1. Schematic illustration for the preparation of PUA resin.

Table 2. Recipes used in the preparation of $\mathrm{MSiO}_{2} / \mathrm{PUA}$ hybrid nanocomposites.

\begin{tabular}{lcccc}
\hline Sample & PUA $(g)$ & EGDMA $(g)$ & $\mathrm{MSiO}_{2}(\mathrm{~g})$ & $\mathrm{AIBN}(\mathrm{g})$ \\
\hline CPUA & 3.72 & 0.242 & 0 & 0.021 \\
PUAS1 & 3.72 & 0.242 & 0.040 & 0.021 \\
PUAS3 & 3.72 & 0.242 & 0.119 & 0.021 \\
PUAS5 & 3.72 & 0.242 & 0.198 & 0.021 \\
\hline
\end{tabular}

pellets method with an average of 24 scans, which collects the spectra at a $4 \mathrm{~cm}^{-1}$ resolution in the wavelength range of 500-4000 $\mathrm{cm}^{-1}$. The X-ray diffraction (XRD) curves were obtained by a reflection scan with monochromatic $\mathrm{CuK} \alpha(\lambda=0.1540 \mathrm{~nm})$ radiation (Bruker-AXS, Germany). Thermogravimetric analysis (TGA) was performed using Polymer Laboratories thermal analyser (TGA 1000, UK) with a heating ramp of $10^{\circ} \mathrm{C} \mathrm{min}^{-1}$ under nitrogen atmosphere at a flow rate of $50 \mathrm{ml} \mathrm{min}{ }^{-1}$. The SEM image of $\mathrm{MSiO}_{2}$ was obtained by scanning electron microscopy (Vega Tescan SEM instrument, Czech Republic). The specimen was prepared by the precipitation of a thin sample layer on a mica surface using a spin coater and its subsequent goldcoating using a sputtering coater. The morphological study of the $\mathrm{MSiO}_{2}$ and composites was carried out by transmission electron microscopy (TEM, TECNAI-12, Philips Co.,
The Netherlands) with an acceleration voltage of $120 \mathrm{kV}$. For this purpose, $\mathrm{MSiO}_{2}$ was mixed in ethanol using an ultrasonic bath for half an hour and then deposited on the lacy grids. In the case of hybrid composites, microtomy was used for cutting a thin layer of samples.

\section{Results and discussion}

FTIR spectra of $\mathrm{SiO}_{2}, \mathrm{MSiO}_{2}$, PUA, CPUA and PUAS5 are presented in figure 3. Accordingly, $\mathrm{SiO}_{2}$ and $\mathrm{MSiO}_{2}$ show a wide absorption peak at $1050-1150$ and $474 \mathrm{~cm}^{-1}$, which originates from $\mathrm{Si}-\mathrm{O}-\mathrm{Si}$ units $[26,27]$. After modification of $\mathrm{SiO}_{2}$ with MPS, some characteristic bands related to MPS can be observed in the spectrum of $\mathrm{MSiO}_{2}$, such as the $\mathrm{C}=\mathrm{C}$ absorption peak at $1520 \mathrm{~cm}^{-1}$ and the $\mathrm{C}=\mathrm{O}$ absorption peak at $1690 \mathrm{~cm}^{-1}[28,29]$. In addition, the stretching vibration of $\mathrm{C}-\mathrm{H}$ moieties is shown at $2855-2935 \mathrm{~cm}^{-1}$, which originates from the methylene groups of MPS. The peak at $1450 \mathrm{~cm}^{-1}$ is also assigned to the bending vibration of $\mathrm{C}-\mathrm{H}$ units in MPS [30,31]. FTIR analysis can also be used for the investigation of the HEMA attachment reaction completion. The absence of the $-\mathrm{N}=\mathrm{C}=\mathrm{O}$ band at near $2270 \mathrm{~cm}^{-1}$ and also the presence of the $\mathrm{N}-\mathrm{H}$ stretching vibration at $3310 \mathrm{~cm}^{-1}$ confirm the successful attachment of HEMA to PU in PUA [32]. There is also a strong peak at near $1715 \mathrm{~cm}^{-1}$ for PUA and 


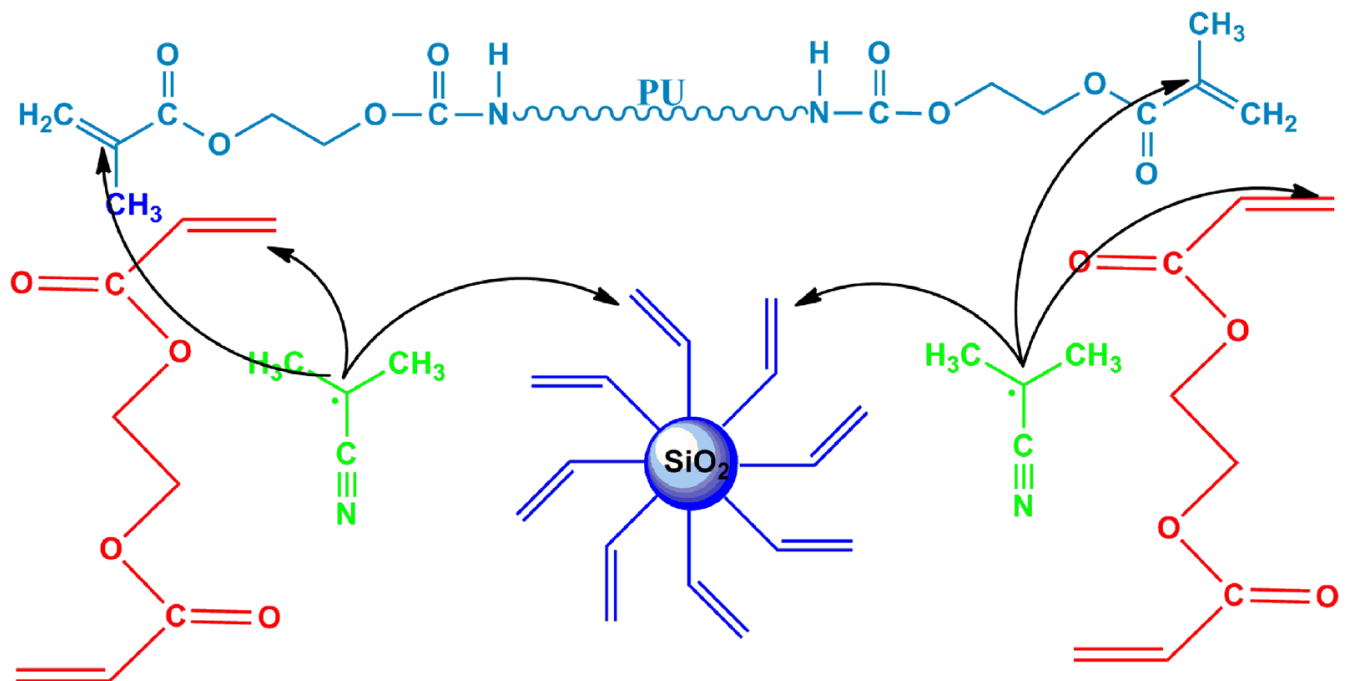<smiles>C=C(C)C(=O)OCCNNC(=O)OCCOCCNNC(=O)OCCOC(=O)C(=C)C</smiles>

Figure 2. Schematic illustration for the preparation of $\mathrm{MSiO}_{2} / \mathrm{PUA}$ hybrid nanocomposites.

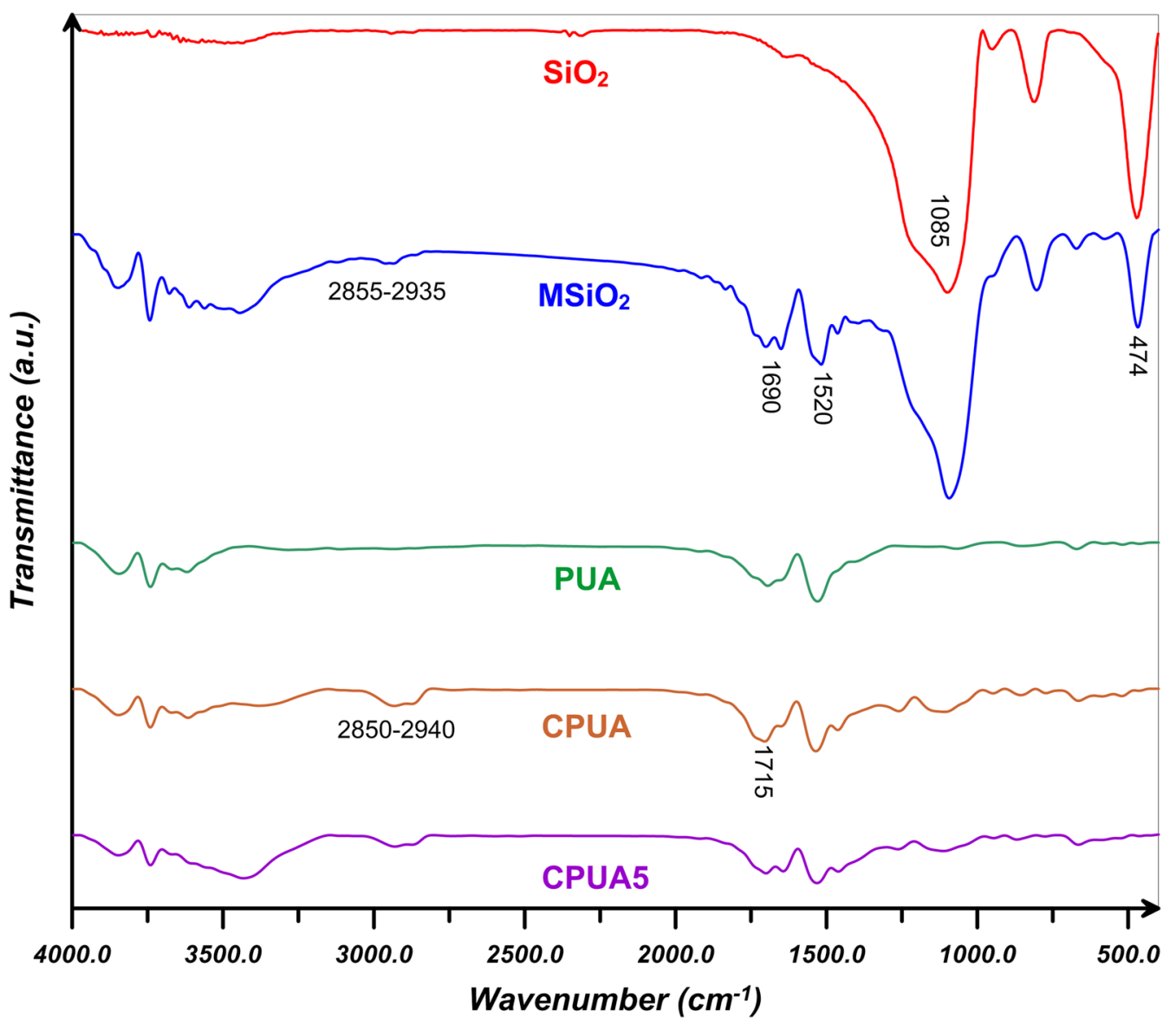

Figure 3. FTIR spectra of $\mathrm{SiO}_{2}, \mathrm{MSiO}_{2}, \mathrm{PUA}, \mathrm{CPUA}$ and PUAS5. 

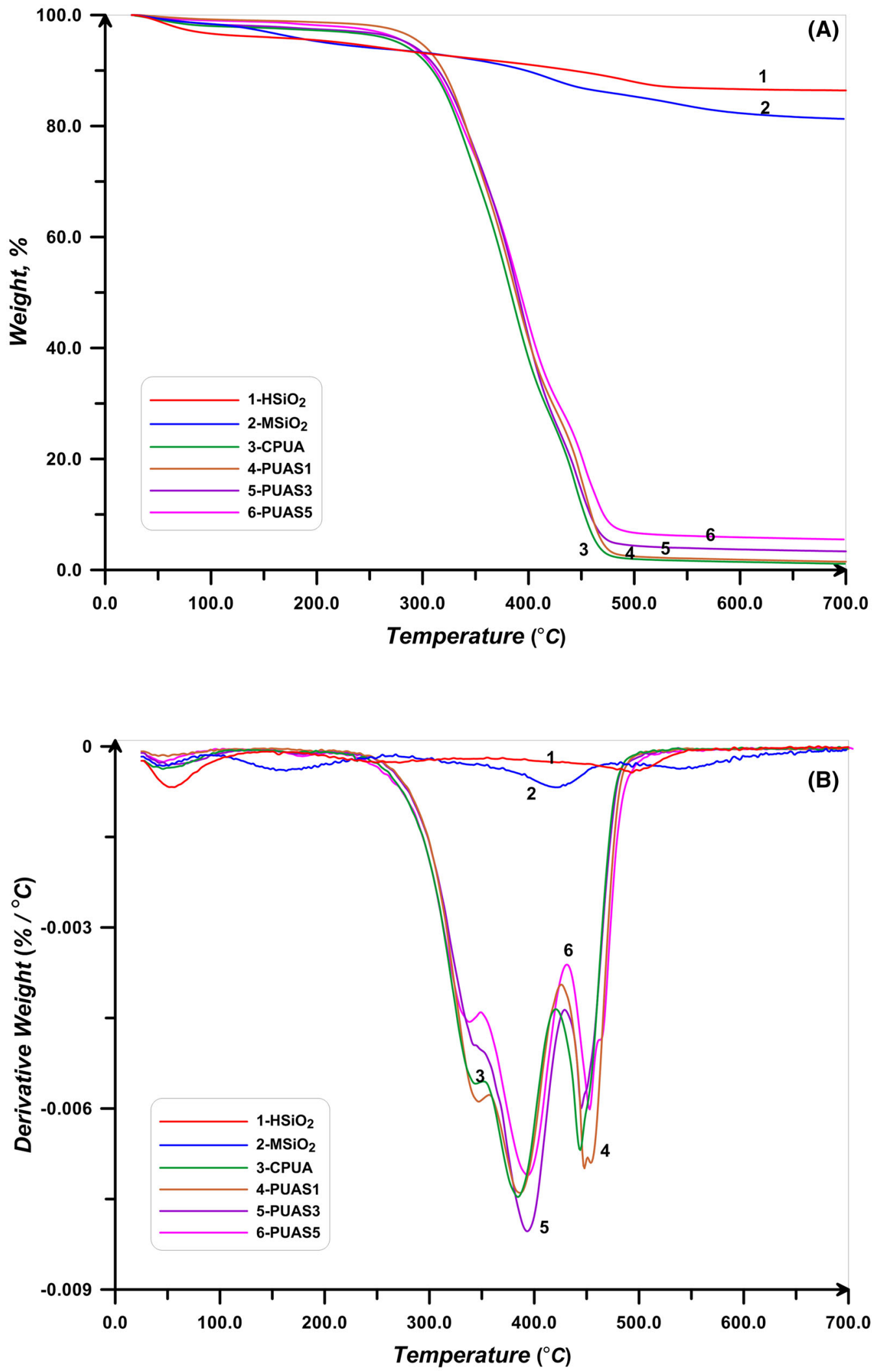

Figure 4. (A) TGA and (B) DTG thermograms of $\mathrm{HSiO}_{2}, \mathrm{MSiO}_{2}, \mathrm{CPUA}, \mathrm{PUAS} 1, \mathrm{PUAS} 3$ and PUAS5. 
CPUA, which correspond to the urethane carbonyl groups. Additionally, the peak at $1460 \mathrm{~cm}^{-1}$ can be assigned to the $\mathrm{C}=\mathrm{C}$ bond of HEMA in PUA [19]. In the CPUA and PUAS5 samples, stretching vibrations of $\mathrm{C}-\mathrm{H}$ groups are shown at $2875-2940 \mathrm{~cm}^{-1}$.

TGA and derivative weight loss (DTG) curves for the $\mathrm{HSiO}_{2}, \mathrm{MSiO}_{2}, \mathrm{CPUA}$ and also $\mathrm{MSiO}_{2} / \mathrm{PUA}$ hybrid composites with different $\mathrm{MSiO}_{2}$ content are displayed in figure $4 \mathrm{~A}$ and $\mathrm{B}$, respectively. The difference between $\mathrm{HSiO}_{2}$ and MPSmodified nanoparticles is significant. For $\mathrm{HSiO}_{2}$, a weight loss around $13.6 \%$ can be observed till $700^{\circ} \mathrm{C}$. The weight loss below $200^{\circ} \mathrm{C}$ originates from the removal of the absorbed water on nanoparticles. The weight loss between 200 and $700^{\circ} \mathrm{C}$ can be attributed to the degradation of $\mathrm{Si}-\mathrm{OH}$ moieties. $\mathrm{MSiO}_{2}$ shows a lower weight loss up to $350^{\circ} \mathrm{C}$ which

Table 3. Summarized TGA and DTG results.

\begin{tabular}{lcc}
\hline Sample & DTG peak $\left({ }^{\circ} \mathrm{C}\right)$ & Char residue $(\%)$ \\
\hline $\mathrm{HSiO}_{2}$ & 52.7 and 493.9 & 86.6 \\
$\mathrm{MSiO}_{2}$ & $162.8,421.7$ and 543.2 & 81.3 \\
$\mathrm{CPUA}$ & $343.8,383.9$ and 443.5 & 1.1 \\
PUAS1 & $347.2,388.4$ and 445.1 & 1.5 \\
PUAS3 & $347.2,393.1$ and 445.7 & 3.5 \\
PUAS5 & $339.2,396.5$ and 454.9 & 5.7 \\
\hline
\end{tabular}

originates from its lower capacity for water adsorption at the surface [33]. However, a considerable weight loss was observed at $350-550^{\circ} \mathrm{C}$, which originates from decomposition of MPS at the surface of $\mathrm{MSiO}_{2}$. Char residue $\mathrm{HSiO}_{2}$ is $86.6 \%$ at $700^{\circ} \mathrm{C}$ which decreases to $81.3 \%$ in the case of $\mathrm{MSiO}_{2}$ as a result of its modifier degradation at higher temperatures. Therefore, MPS content in $\mathrm{MSiO}_{2}$ can be estimated to be $5.3 \%$. In the case of hybrid composites (figure $4 \mathrm{~A}$ ), the slight weigh loss at relatively low temperatures (lower than $250^{\circ} \mathrm{C}$ ) is because of humidity evaporation. The weight loss at $320-500^{\circ} \mathrm{C}$ originates from the decomposition of PUA chains [5,21]. In these samples, hydrogen bonding is a physical crosslinker resulting in improved thermal stabilities. Additionally, three-dimensional network formation upon the radical crosslinking process is another reason for increased thermal stabilities [34]. All the hybrids show three major degradation steps, both of them in $320-430^{\circ} \mathrm{C}$ and another one in $420-500^{\circ} \mathrm{C}$. This shows that decomposition of PUA chains starts at $320-420^{\circ} \mathrm{C}$ at the HDI hard segments with breakage of urethane units. The decomposition step at $420-500^{\circ} \mathrm{C}$ can be assigned to the decomposition of PEG soft segments and of PUA [35-38]. TGA curves and the extracted results in table 3 show that higher $\mathrm{MSiO}_{2}$ content in the nanocomposites results in higher char residues and also thermal degradation temperatures in each step. For example, PUAS5 shows the main decomposition temperatures of 396.5 and $454.9^{\circ} \mathrm{C}$ and also

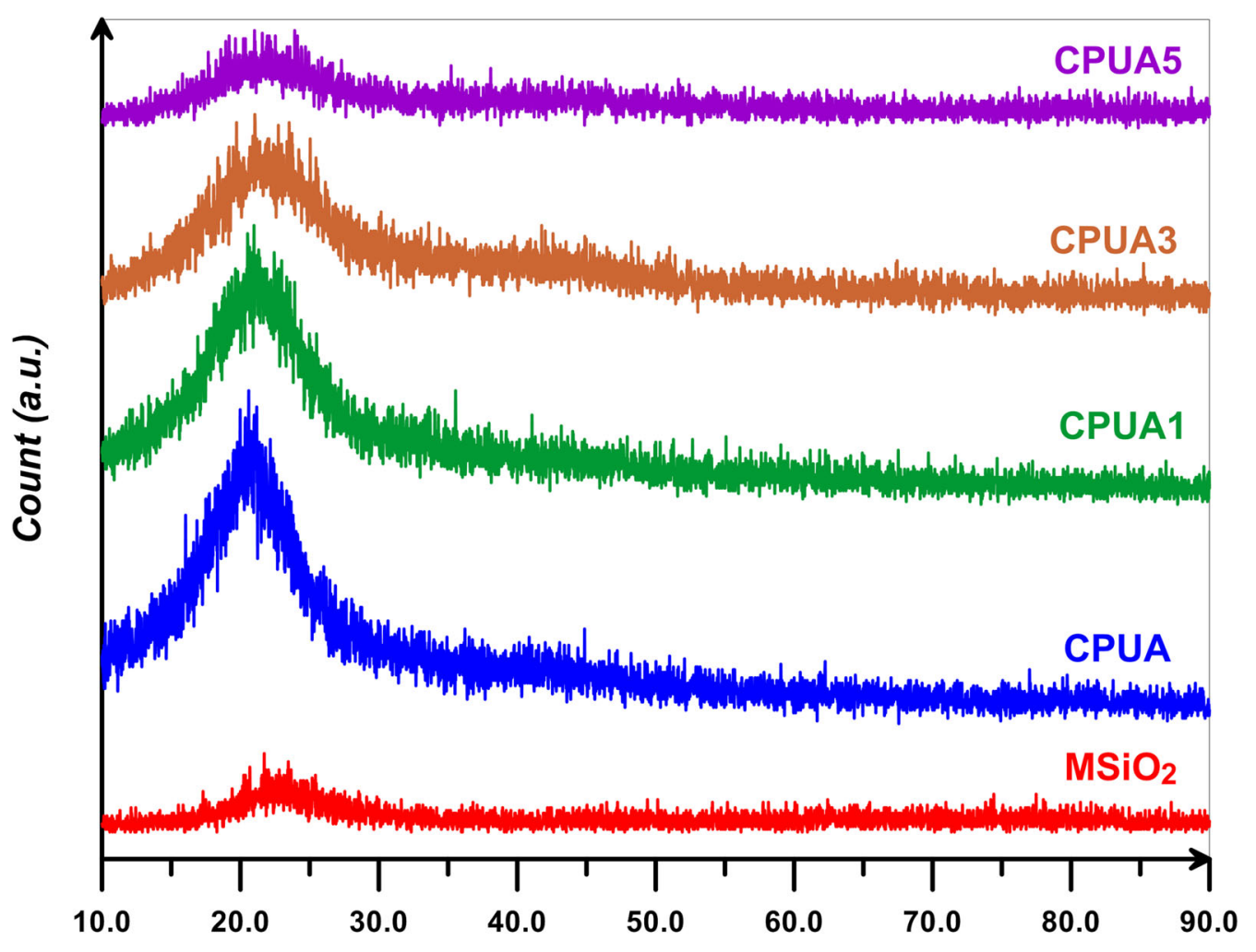

2- Theta

Figure 5. XRD curves of $\mathrm{MSiO}_{2}, \mathrm{CPUA}, \mathrm{PUAS} 1, \mathrm{PUAS} 3$ and PUAS5. 


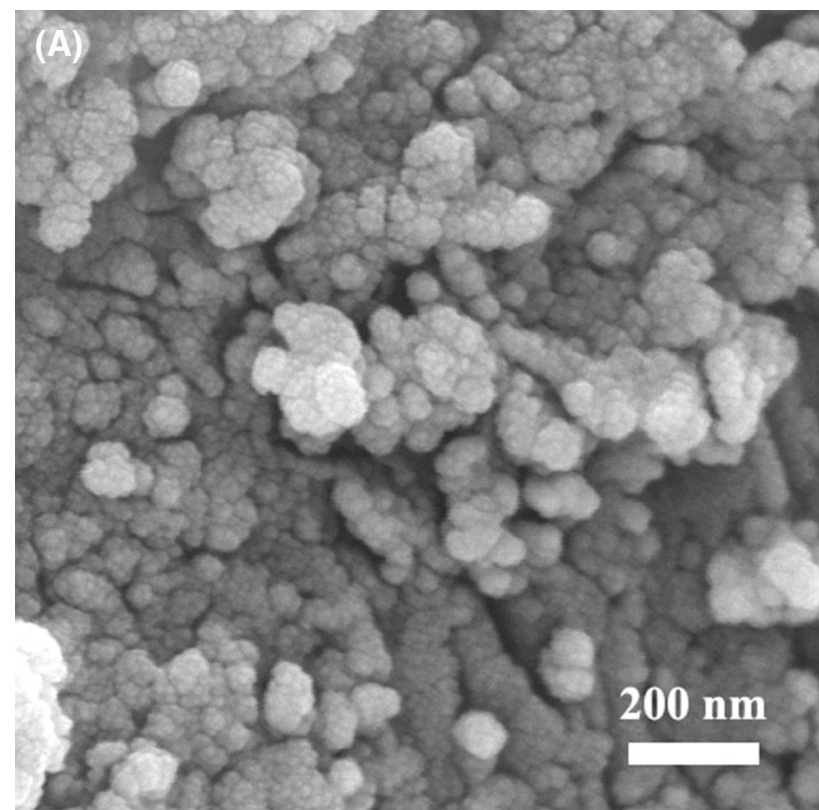

(B)
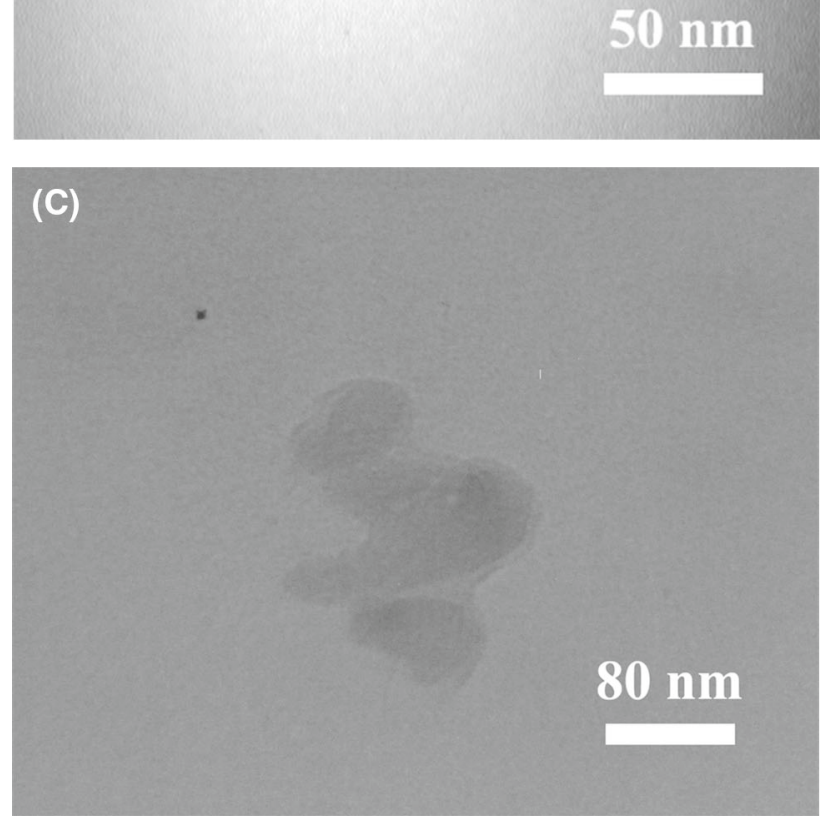

Figure 6. (A) SEM, (B) TEM images of $\mathrm{MSiO}_{2}$ and (C) TEM image of PUAS5. char content of $5.7 \%$ at $700^{\circ} \mathrm{C}$. The high amount of $\mathrm{MSiO}_{2}$ can also be resulted in higher degree of crosslinking and therefore, higher thermal stabilities and char residue.

The XRD patterns for $\mathrm{MSiO}_{2}, \mathrm{CPUA}$ and $\mathrm{SiO}_{2} / \mathrm{PUA}$ nanocomposites with different amounts of $\mathrm{MSiO}_{2}$ are displayed in figure 5. In the case of $\mathrm{MSiO}_{2}$, a broad peak at around $23^{\circ}$ is observed, which is attributed to the amorphous structure of silica domains. In the case of CPUA powder, a broad diffraction peak at near $20^{\circ}$ is assigned to the amorphous phase of cured PUA. Additionally, all the nanocomposites with different amounts of $\mathrm{MSiO}_{2}$ show a diffraction peak at about $20^{\circ}$ as a result of the presence of small crystalline structures and partial ordered arrangement of PU chain segments. Flexible and linear polyether chains of PEG and the symmetric structure of HMDI can be resulted in crystalline structures [39-41]. The peak intensity of nanocomposites is lower in comparison with CPUA and it decreases with increasing $\mathrm{MSiO}_{2}$ content, which confirms the existence of a strong interaction among PUA and $\mathrm{MSiO}_{2}$ in the cured nanocomposites [42]. The partial ordered arrangement of PU chain segments decreases with increasing $\mathrm{MSiO}_{2}$ content and therefore, the peak intensity is diminished.

$\mathrm{MSiO}_{2}$ was dispersed in ethanol and gold-coated to record SEM images (figure 6A). Also, $\mathrm{MSiO}_{2}$ dispersion in ethanol was deposited on lacy carbon grids for taking TEM images (figure 6B). Finally, by cutting a thin layer from PUAS5 with a thickness of about $70 \mathrm{~nm}$, the sample was prepared for TEM imaging (figure 6C). According to the images, MPSmodified silica nanoparticles with a size in the range of several nanometres are in an aggregated form. In the case of PUAS5, $\mathrm{MSiO}_{2}$ nanoparticles were pushed apart during the mixing and curing reactions. $\mathrm{MSiO}_{2}$ can be observed as spherical nanoparticles within the dark matrix of PUAS5. This shows that $\mathrm{MSiO}_{2}$ was homogenously distributed in the PUA matrix $[26,27]$.

\section{Conclusion}

Hybrid composites of PUA and $\mathrm{MSiO}_{2}$ were prepared by the radical method using different amounts of $\mathrm{MSiO}_{2}$ and also the EGDMA crosslinker. After modification of $\mathrm{SiO}_{2}$ with MPS, some characteristic bands related to MPS can be observed in the spectrum of $\mathrm{MSiO}_{2}$. The absence of the $-\mathrm{N}=\mathrm{C}=\mathrm{O}$ band at near $2270 \mathrm{~cm}^{-1}$ and also the appearance of the $\mathrm{N}-\mathrm{H}$ stretching vibration at $3310 \mathrm{~cm}^{-1}$ confirm the successful attachment of HEMA to PU in PUA. Three-dimensional network formation upon the radical crosslinking process is a reason for increased thermal stabilities. Decomposition of PUA chains starts at $320-420^{\circ} \mathrm{C}$ at the HDI hard segments. The decomposition step at $420-500^{\circ} \mathrm{C}$ is associated with the decomposition of PEG soft segments and PUA. With the addition of the $\mathrm{MSiO}_{2}$ content in the nanocomposite matrix, char residue and thermal degradation temperature were increased. PUAS5 shows the 
main decomposition temperatures of 396.5 and $454.9^{\circ} \mathrm{C}$ and also char content of $5.7 \%$ at $700^{\circ} \mathrm{C}$. A broad XRD diffraction peak at near $20^{\circ}$ for CPUA is related to the amorphous phase of cured PUA. Aggregated nanoparticles of $\mathrm{MSiO}_{2}$ with a size in the range of several nanometres were pushed apart and homogenously dispersed in the PUA matrix. The TEM image of PUAS5 showed that $\mathrm{MSiO}_{2}$ was homogenously distributed within the PUA matrix.

\section{Acknowledgements}

Financial support of the Iran National Science Foundation (INSF) is highly appreciated under grant no. 95839965.

\section{References}

[1] Chattopadhyay D K and Raju K V S N 2007 Prog. Polym. Sci. 32352

[2] Engels H W, Pirkl H G, Albers R, Albach R W, Krause J, Hoffmann A et al 2013 Angew. Chem. Int. Ed. 529422

[3] Cao X, Lee L J, Widy T and Macosko C 2005 Polymer 46 775

[4] Zhang T, Wu W, Wang X and Mu Y 2010 Prog. Org. Coat. 68 201

[5] Wang Z, Gao D, Yang J and Chen Y 1999 J. Appl. Polym. Sci. 732869

[6] Peruzzo P J, Anbinder P S, Pardini O R, Vega J, Costa C A, Galembeck F et al 2011 Prog. Org. Coat. 72429

[7] Wang F, Hu J Q and Tu W P 2008 Prog. Org. Coat. 62245

[8] Oh I S, Park N H and Suh K D 2000 J. Appl. Polym. Sci. 75 968

[9] Alishiri M, Shojaei A and Abdekhodaiea M J 2016 RSC Adv. 6 8743

[10] Ha H, Kim S C and Ha K 2010 Macromol. Res. 18674

[11] Chen C, Justice R S, Schaefer D W and Baur J W 2008 Polymer 493805

[12] Azimi R, Roghani-Mamaqani H and Gholipour-Mahmoudalilou M 2017 Polymer 126152

[13] Barus S, Zanetti M, Lazzari M and Costa L 2009 Polymer 50 2595

[14] Goda H and Frank C W 2001 Chem. Mater. 132783

[15] Zou H, Wu S and Shen J 2008 Chem. Rev. 1083893

[16] Han Y, Dong W, Chen Z and Xin Z 2016 Mater. Res. Innov. 20 247

[17] Mousavi A, Roghani-Mamaqani H, Salami-Kalajahi M, Shahi S and Abdollahi A 2018 Express Polym. Lett. 12 187
[18] Abdollahi A, Roghani-Mamaqani H, Salami-Kalajahi M, Mousavi A, Razavi B and Shahi S 2018 Prog. Org. Coat. 117 154

[19] Qiu F, Xu H, Wang Y, Xu J and Yang D 2012 J. Coat. Technol. Res. 9503

[20] Wang X, Hu Y, Song L, Xing W, Lu H, Lv P et al 2011 J. Polym. Res. 18721

[21] Yu B, Wang X, Xing W, Yang H, Song L and Hu Y 2012 Ind. Eng. Chem. Res. 5114629

[22] Mousavi A, Roghani-Mamaqani H, Salami-Kalajahi M, Shahi S and Abdollahi A 2018 Mater. Chem. Phys. 216468

[23] Abdollahi A, Roghani-Mamaqani H, Salami-Kalajahi M, Razavi B, Mousavi A and Shahi S 2018 Polym. Compos. 39 E2316

[24] Jiang J C J, Wang W, Shen H and Wang J 2016 Appl. Surf. Sci. 397104

[25] Stöber W, Fink A and Bohn E 1968 J. Colloid Interface Sci. 2662

[26] Mirshafiei-Langari S A, Haddadi-Asl V, Roghani-Mamaqani H, Sobani M and Khezri K 2013 J. Polym. Res. 20163

[27] Mirshafiei-Langari S A, Haddadi-Asl V, Roghani-Mamaqani H, Sobani M and Khezri K 2013 Polym. Compos. 341648

[28] Roghani-Mamaqani H, Haddadi-Asl V, Khezri K, Zeinali E and Salami-Kalajahi M 2014 J. Polym. Res. 21333

[29] Roghani-Mamaqani H, Haddadi-Asl V, Khezri K and SalamiKalajahi M 2014 Polym. Int. 631912

[30] Roghani-Mamaqani H, Haddadi-Asl V, Ghaderi-Ghahfarrokhi M and Sobhkhiz M 2014 Colloid Polym. Sci. 2922971

[31] Roghani-Mamaqani H and Haddadi-Asl V 2014 Polym. Compos. 35386

[32] Lee S I, Hahn Y B, Nahm K S and Lee Y S 2005 Polym. Adv. Technol. 16328

[33] Jiang J, Wang W, Shen H, Wang J and Cao J 2017 Appl. Surf. Sci. 397104

[34] Hu T, Chen S, Tian Y, Pojman J A and Chen L 2006 J. Polym. Sci. A: Polym. Chem. 443018

[35] Patel A and Mequanint K 2011 J. Bioactive Compat. Polym. 26 114

[36] Zhang Q, Huang C, Wang H, Hu M, Li H and Liu X 2016 RSC Adv. 6107942

[37] Petrovic Z S, Zavargo Z, Flynn J H and Macknight W J 1994 J. Appl. Polym. Sci. 511087

[38] Gaikwad M S, Gite V V, Mahulikar P P, Hundiwale D G and Yemul O S 2015 Prog. Org. Coat. 86164

[39] Mo M, Zhao W, Chen Z, Yu Q, Zeng Z and Wu X 2015 RSC Adv. 556486

[40] Liu H, Gao J, Huang W, Dai K, Zheng G and Liu C 2016 Nanoscale 812977

[41] Wang C, Ma C, Mu C and Lin W 2017 RSC Adv. 727522

[42] Zhang S, Jiang J, Yang C, Chen M and Liu X 2011 Prog. Org. Coat. 701 